\title{
Configuración constitucional y tutela de la autonomía local
}

\author{
Guillermo Jiménez Sánchez \\ Magistrado del Tribunal Constitucional
}

\begin{abstract}
SUMARIO: I. INTRODUCCIÓN.- II. LA AUTONOMÍA LOCAL EN LA CONSTITUCIÓN ESPAÑOLA. A) Preceptos constitucionales que fundamentan la autonomía local. B) «Perspectivas» de la autonomía local. C) La esfera competencial de los Entes Locales. Marco constitucional y concreciones normativas. D) El núcleo esencial e indisponible de la autonomía local. a) La referencia constitucional de las competencias de los Entes Locales. b) Las dimensiones políticas, social y administrativa de la autonomía local. 1) La dimensión política de la autonomía local. 2) La dimensión social de la autonomía local. 3) La dimensión administrativa de la autonomía local.- III. LA PROTECCIÓN JURISDICCIONAL DE LA AUTONOMÍA LOCAL. A) Consideraciones generales. B) La tutela de la autonomía local frente a las vulneraciones producidas por actuaciones administrativas. a) Las actividades administrativas impugnables. b) Los sujetos de las actividades administrativas impugnables. C) La tutela de la autonomía local frente a las disposiciones generales que la lesionen. D) La supresión de los controles previos de legalidad sobre los actos y disposiciones de las Corporaciones Locales. IV. EL TRIBUNAL CONSTITUCIONAL, GARANTE DE LA AUTONOMÍA LOCAL. A) Las vías para conseguir la tutela de la autonomía local por el Tribunal Constitucional hasta la reforma introducida en la Ley Orgánica de éste por la Ley Orgánica 7/1999, de 21 de abril. B) El conflicto en defensa de la autonomía local. a) Consideraciones generales. b) Legitimación para el planteamiento del conflicto. c) Tramitación del conflicto. d) Canon de enjuiciamiento. e) Resolución del conflicto.
\end{abstract}

\section{INTRODUCGIÓN}

No por dar cumplimiento a un, por lo demás grato, deber de cortesía, sino para exteriorizar unos sentimientos muy sinceros, debo iniciar mis palabras esta cálida tarde dejando constancia expresa de la alegría que me produce ocupar esta tribuna y de mi profundo agradecimiento por la cordial invitación de la que ello trae causa. 
Creo que no necesita mayor justificación que me declare particularmente satisfecho, alegre, por participar en las actividades de la Academia Sevillana del Notariado, de la que con orgullo ostento el título de miembro honorario y a la que me considero estrechamente vinculado, aun cuando la distancia geográfica que separa su sede de la ciudad en la que por ineludibles exigencias del desempeño de mis actuales funciones paso la mayor parte de mis días me impida concurrir a los actos que celebra tan asiduamente como, enriqueciéndome en términos que nunca agradeceré suficientemente, lo hice durante las dos últimas décadas de ese tan próximo (pero, en definitiva e inexorablemente, ya pretérito) Siglo XX. Y, como no podía ser menos, mi alegría ha de venir acompañada del agradecimiento (el ser agradecidos es de bien nacidos) a quienes, sin duda movidos por el recuerdo de tareas compartidas y por el generoso impulso de una vieja amistad, me han brindado el privilegio de reanudar un tracto, si no interrumpido, al menos peligrosamente dilatado.

Junto a lo hasta aquí apuntado entiendo necesario, asimismo, hacer patente que solicito su indulgencia por haber elegido como tema de mi intervención en esta sesión de clausura del curso 2002/2003 el de la configuración constitucional y tutela de la autonomía local. Como consecuencia lógica de las exigencias de mis presentes responsabilidades normalmente he de enfrentarme con temas muy distantes de los propios y característicos del Derecho patrimonial privado y, específicamente, de los reconducibles a la esfera propia del Derecho del tráfico mercantil y del estatuto y régimen de sus protagonistas (los empresarios), que durante el tiempo en que he ejercido la docencia han sido los que primordialmente han requerido mi atención. Dada mi actual falta de «rodaje» en el tratamiento de ese sector del Ordenamiento jurídico, pretender afrontar en esta Casa, con el obligado rigor y la deseable altura científica, alguna de las cuestiones que en él se proponen seguramente sería una empresa forzosamente avocada al fracaso, en la cual habría de desempeñar un muy pobre papel, lo que no sería, desde luego, ni sorprendente ni siquiera (muy probablemente) lamentable, pero en la que ocuparía su valioso tiempo de forma muy poco útil, lo que sí constituiría ya sobrado motivo para dirigirme bien fundados reproches.

Las cuestiones que proponen la configuración constitucional y la tutela de la autonomía local fueron objeto de amplio debate en una reunión tripartita de los miembros de los Tribunales Constitucionales de Italia, Portugal y España celebrada durante el mes de noviembre el pasado año en Madrid, reunión en la cual intervine como portavoz de la delegación española. Sin duda dichas cuestiones no han merecido, ni en el plano político ni en el académico, una atención tan significativa e intensa como la suscitada por otras tam- 
bién atinentes a la vertebración del Poder Público en los diferentes ámbitos territoriales que contempla nuestra Constitución, singularmente aquellos que hacen referencia a la configuración del Estado como «Estado Autonómico» en virtud del destacado papel que en él se atribuye a las Comunidades Autónomas. Pero seguramente no pueden estimarse carentes de interés, y en la actualidad están reclamando, cada vez con mayor intensidad, la atención de políticos y de juristas porque, en última instancia, la vida local constituye el marco más inmediato en el que se desarrolla la vida de los ciudadanos (que de su inserción en una comunidad cívica reciben ese significativo título), y sólo si los valores y los principios básicos que presiden la configuración democrática del Estado se hacen plenamente presentes en la vida local podrá aquél entenderse definitivamente asentado y sólidamente enraizado.

Por ello, aun cuando el tema sobre el que les propongo que nos detengamos unos momentos pueda resultar algo alejado de los que con mayor frecuencia se abordan en las conferencias y seminarios de nuestra Academia, me he permitido elegirlo como objeto de mi intervención, algo tranquilizado, además, por la consideración de que la apertura con la que esta docta Casa ha contemplado siempre los estudios de carácter jurídico nos ha llevado en otras ocasiones a quienes hemos participado en sus trabajos a enfrentarnos con el análisis de temas y problemas propios del campo del Derecho público, como los de carácter fiscal o los de naturaleza urbanística.

\section{LA AUTONOMÍA LOCAL EN LA CONSTITUCIÓN ESPAÑOLA}

\section{A) PRECEPTOS CONSTITUCIONALES QUE FUNDAMENTAN LA AU- TONOMÍA LOCAL}

La aproximación al concepto de autonomía local ha de partir necesariamente de su proclamación en los artículos 137, 140 y 141 C.E. Pero, a diferencia de lo que sucede con la autonomía que se proclama de las Comunidades Autónomas, la Constitución española no contiene un desarrollo constitucional de la autonomía local tan amplio como el consagrado respecto de la autonomía de los Entes Autonómicos. Las pautas para precisar el alcance de la autonomía local vienen constituidas por la ubicación sistemática de la normativa que hace referencia a ella en el título correspondiente a la Organización territorial del Estado y por el contenido de algunos preceptos específicos que, sin embargo, no permiten dotar a la autonomía local de un contenido indiscutible y suficiente. 
Tales preceptos son:

* El artículo 137, el cual dispone que «el Estado se organiza territorialmente en Municipios, en Provincias y en las Comunidades Autónomas que se constituyan. Todas estas entidades gozan de autonomía para la gestión de sus respectivos intereses».

* El artículo 140, de acuerdo con el cual «la Constitución garantiza la autonomía de los Municipios. Estos gozarán de personalidad jurídica plena. Su gobierno y administración corresponde a sus respectivos Ayuntamientos, integrados por los Alcaldes y los Concejales. Los Concejales serán elegidos por los vecinos del Municipio mediante sufragio universal, igual, libre, directo y secreto, en la forma establecida por la ley. Los Alcaldes serán elegidos por los Concejales o por los vecinos. La ley regulará las condiciones en las que proceda el régimen del concejo abierto».

* El artículo 141, que define en su apartado 1 a la Provincia como «una entidad local con personalidad jurídica propia, determinada por la agrupación de Municipios y división territorial para el cumplimiento de las actividades del Estado. Cualquier alteración de los límites Provinciales habrá de ser aprobada por las Cortes Generales mediante ley orgánica». «El gobierno y la administración autónoma de las Provincias [según dispone el apartado 2 del mismo artículo] estarán encomendados a Diputaciones u otras Corporaciones de carácter representativo». Es posible «crear agrupaciones de Municipios diferentes de la Provincia» (art. 141.3), y, «en los archipiélagos, las islas tendrán además su administración propia en forma de Cabildos o Consejos» (art. 141.4).

* El artículo 142, que, como garantía para el cumplimiento de las funciones de la Administración Local, proclama en los siguientes términos el principio de suficiencia financiera: «Las Haciendas locales deberán disponer de los medios suficientes para el desempeño de las funciones que la ley atribuye a las Corporaciones respectivas y se nutrirán fundamentalmente de tributos propios y de participación en los del Estado y de las Comunidades Autónomas».

* Y, finalmente, el artículo 133.2, el cual, en el titulo dedicado a Economía y Hacienda, dispone que: «las Comunidades Autónomas y las Corporaciones Locales podrán establecer y exigir tributos, de acuerdo con la Constitución y las leyes». 


\section{B) «PERSPECTIVAS» DE LA AUTONOMÍA LOCAL}

En el contenido de estos enunciados, notablemente heterogéneo, cabe apreciar las siguientes dimensiones o perspectivas:

a) Una perspectiva territorial o estatalista (los Entes Locales resultan concebidos como unidades territoriales del Estado).

b) Una perspectiva funcional (que se concreta en el reconocimiento a los Entes Locales de «autonomía para la gestión de sus respectivos intereses»).

c) Una perspectiva democrática (que atiende al sistema de nombramiento de los integrantes de los órganos de gobierno de los Entes Locales).

d) Y, por último, una perspectiva financiera (que garantiza a los Entes Locales la suficiencia de recursos para el desarrollo de las funciones que les resultan propias).

Como consecuencia de lo anterior cabe afirmar que existencia necesaria, ámbito funcional propio y composición democrática de sus órganos de gobierno son los elementos definitorios de los Entes Locales. Estos elementos, justamente, son los que concurren en el Estado (o, si se quiere, en el Estado Central), y cabe afirmar que son, al menos en algún y no irrelevante sentido, más de los que pueden predicarse de las Comunidades Autónomas, cuya existencia es sólo contingente (como claramente resulta de lo establecido en el art. 143.1 C.E.).

\section{C) LA ESFERA COMPETENCIAL DE LOS ENTES LOCALES. MARCO CONSTITUCIONAL Y CONCRECIONES NORMATIVAS}

Ahora bien, a diferencia del trato que la Constitución española dispensa al Estado central y a las Comunidades Autónomas, definiendo el ámbito de sus intereses respectivos y los instrumentos a través de los cuales ha de verificarse esa gestión, en el caso de los Entes Locales la Constitución se ha limitado a reconocerles la gestión autónoma de unos intereses que no define mediante la asignación de competencias propias. Dicho de otro modo, los Entes Locales tendrán las competencias que les asigne el legislador, obligado, eso sí, pero casi exclusivamente sólo, a respetar una autonomía que la Constitución se limita a proclamar. La autonomía funcional del Estado y de las Comunidades Autónomas es, por tanto, el resultado del ejercicio de un haz de competencias 
asignadas por el «bloque de la constitucionalidad», en tanto que la autonomía local opera como un prius, como una pauta para cuya satisfacción habrán de asignarse competencias en el nivel de la legalidad, sin disponer para ello de otra orientación que la dispensada por un principio de contenido evanescente pero que, no obstante, la jurisprudencia constitucional ha tratado de definir en su contenido y en su alcance.

Así, ya la temprana STC 32/1981, de 28 de julio, se ocupó de señalar que la necesaria existencia de ciertas instituciones por imperativo constitucional (lo que las hace beneficiarias de una trascendental garantía institucional) no asegura un contenido concreto o un ámbito competencial determinado y fijado de una vez por todas, sino únicamente la preservación de una institución en términos recognoscibles para la imagen que de ella tiene la conciencia social en cada tiempo y lugar, de suerte que, con este límite, la configuración institucional concreta de la institución queda deferida al legislador ordinario. En esto reside la diferencia de tratamiento jurídico-constitucional entre los Entes Locales y las instituciones supremas del Estado, puesto que la regulación orgánica de estas últimas se encuentra residenciada en la propia Lex legum.

La dimensión constitucional de la autonomía de Municipios y Provincias se agota, pues, en la garantía del núcleo esencial de competencias y funciones atribuidas a estos Entes, configurado con carácter indisponible por el legislador, al cual sólo viene atribuida la función de concretar las competencias y las funciones de las instituciones locales dentro de los límites representados por la prohibición de desfigurar la imagen comúnmente aceptada de la autonomía local.

\section{D) EL NÚCLEO ESENCIAL E INDISPONIBLE DE LA AUTONOMÍA LOCAL}

Precisar el contenido de ese núcleo esencial e indisponible no es, desde luego, cuestión sencilla, pero del propio texto constitucional pueden derivarse algunas premisas de difícil discusión.

a) La referencia constitucional de las competencias de los Entes Locales.

En primer lugar, los Municipios y las Provincias son "Poder Público constituido". El modelo español se separa en su fundamento mismo de la ficción teórica del pouvoir municipal, que parte de la consideración de la autonomía local como expresión de un principio de libertad de unas comunidades preconstitucionales frente al Estado. Al margen de su substrato sociológico y de 
su tradición histórica, la existencia de los Municipios y de las Provincias como entes territoriales trae causa directa (origen y fundamento normativo) exclusivamente de la Constitución, sin que exista un supuesto derecho de cada concreta comunidad vecinal a convertirse en Municipio, del mismo modo que las Provincias y los Municipios existentes no pueden pretender la titularidad de derecho alguno al mantenimiento de la actual división Municipal y Provincial. Debe haber, de conformidad con la Constitución, Municipios y Provincias, pero no necesariamente los concretos Municipios y Provincias que en cada momento existen. Por otra parte, en virtud de ese mismo fundamento constitucional (exclusivo) de su existencia, que deja huérfanos a los Entes Locales de otras fuentes de legitimación de su ser jurídico, no queda en absoluto excluida la posibilidad de que aquéllos y éstas (los Municipios y las Provincias) convivan con otras entidades territoriales. Ahora bien, la creación de estas últimas, tal como tuvo ocasión de afirmar la STC 32/1981, de 28 de julio, no puede implicar la abolición por entero de los Entes Locales cuya autonomía está constitucionalmente garantizada, pues el legislador puede disminuir o acrecentar las competencias existentes en cada momento, pero no eliminarlas por entero.

b) Las dimensiones políticas, social y administrativa de la autonomía lo$\underline{\text { cal. }}$

En segundo lugar, el entendimiento de lo que sea ese núcleo mínimo de la autonomía local constitucionalmente garantizado ha de partir de la dimensión política, administrativa y social de tal autonomía.

\section{1) LA DIMENSIÓN POLÍTICA DE LA AUTONOMÍA LOCAL}

En efecto, el principio democrático y el valor del pluralismo político, conforme a los cuales se designa a los integrantes de los órganos de gobierno de los Entes Locales, confiere a éstos un significado que los diferencia cualitativamente de las entidades administrativas y los erige en instrumentos para la participación en el ejercicio del poder político (en este sentido se ha expresamente pronunciado la STC 4/1981, de 2 de febrero, en su fundamento jurídico 3). Los Municipios y las Provincias forman parte, pues, siguiendo la terminología italiana, del Estado-comunidad, y el poder que a su través se ejercita es un verdadero poder político, como no puede ser menos, atendida la elección por sufragio de sus representantes.

Ciertamente la autonomía local suele distinguirse de la que disfrutan las Comunidades Autónomas tomando como criterio de referencia el disfrute de la potestad legislativa y viendo sólo en ésta un instrumento genuino de la ac- 
tuación política. Del hecho de que los Ayuntamientos no dicten leyes se concluye, en definitiva, que el poder municipal es sólo poder administrativo. Sin embargo el componente democrático de los Entes Locales, que sin ir más lejos ha sido tomado en cuenta para moderar las exigencias de la reserva de ley en materia tributaria local, o incluso en el ámbito sancionador (véanse, por todas, las SSTC 233/1999, de 16 de diciembre, y 132/2001, de 8 de junio de 2001), les habilita para la gestión de sus intereses propios con arreglo a directrices de orientación política también propias, lo que claramente los distancia de la figura de los meros entes administrativos descentralizados. La autonomía local implica, así, una suerte de indirizzo político constitucionalmente garantizado.

\section{2) LA DIMENSIÓN SOCIAL DE LA AUTONOMÍA LOCAL}

De otro lado la opción por un Estado social supone, esencialmente, la opción por un Estado prestacional e interventor. Superada la concepción liberal del Estado, que reducía las obligaciones de éste a poco más que al mantenimiento del orden público, y permitía cierta identificación de la incipiente actividad prestacional con las Corporaciones Locales, la demanda de actuaciones positivas a favor de los ciudadanos se extiende hoy a la totalidad de los Poderes Públicos, incluidos los Entes Locales. Y acaso cabe decir que los principios de descentralización y eficacia administrativa se convierten en razones de primer orden para justificar la atribución de competencias sociales a las Provincias y a los Municipios.

\section{3) LA DIMENSIÓN ADMINISTRATIVA DE LA AUTONOMÍA LOCAL}

Por lo que hace a la dimensión administrativa o jerárquica del modelo de Estado es evidente que la autonomía local no confiere un poder ilimitado y libre. La cláusula del Estado de Derecho y, antes aún, la unidad del Ordenamiento imponen la necesidad del sometimiento a la ley como límite inherente a toda actuación política y administrativa. Así, destacando que la autonomía hace referencia a un poder limitado, rasgo que la distingue de la soberanía, se declaró en la ya citada STC 4/1981, de 28 de julio (fundamento jurídico 3): «que el principio de autonomía es compatible con la existencia de un control de legalidad sobre el ejercicio de las competencias, si bien entendemos que no se ajusta a tal principio la previsión de controles genéricos e indeterminados que sitúen a las Entidades Locales en una posición de subordinación o dependencia cuasi jerárquica de la Administración del Estado u otras Entidades territoriales. En todo caso, los controles de carácter puntual habrán de referirse normalmente a supuestos en que el ejercicio de las competencias de la 
Entidad Local incidan en intereses generales concurrentes con los propios de la entidad, sean del Municipio, la Provincia, la Comunidad Autónoma o el Estado. [...] En cambio, la autonomía garantizada por la Constitución quedaría afectada en los supuestos en que la decisión correspondiente a "la gestión de los intereses respectivos" fuera objeto de un control de oportunidad de forma tal que la toma de la decisión viniera a compartirse por otra Administración $[\ldots] »$.

\section{LA PROTECGIÓN JURISDICGIONAL DE LA AUTONOMÍA LOCAL}

\section{A) CONSIDERACIONES GENERALES}

El encaje sistemático de la autonomía local en una sede distinta al capítulo que la Constitución Española dedica a los derechos fundamentales determina directamente que su defensa frente a actos o disposiciones normativas de rango inferior a Ley que la lesionen haya de desenvolverse ante la Jurisdicción Contencioso-Administrativa y sólo ante ella, pues, dado que en la Constitución no se configura la autonomía local como un derecho fundamental, no cabe demandar su protección a través del recurso de amparo. En tanto que Poderes Públicos, los Entes Locales tienen una situación especial respecto de los derechos fundamentales, sobre los cuales exclusivamente se les reconoce la titularidad con significativos matices y limitaciones (véase, por todas, la STC 175/2001, de 26 de julio), de manera que únicamente pueden, en principio, defender su autonomía (que hemos ya calificado de garantía institucional) a través del ejercicio del derecho a la tutela judicial (art. 24 C.E.), al que pueden acogerse porque en el artículo 24 de la Constitución se inscribe una verdadera garantía objetiva de los procesos judiciales, de la que disfruta cualquier parte procesal por el solo hecho de serlo. En definitiva, la defensa de la autonomía local queda, como regla general, al margen del mecanismo extraordinario de protección que representa el recurso de amparo, al cual sólo podrá acudirse en el caso de que resulten lesionados derechos procesales en el curso del procedimiento ordinario en el que se persiga la tutela de aquella garantía institucional. Pero esta tutela únicamente podrá invocarse en defensa de los derechos procesales a que se acaba de hacer referencia, no en virtud de las exigencias de respeto de una autonomía que, en cuanto tal, no se ha configurado constitucionalmente como un derecho fundamental.

Se residencia así en la jurisdicción ordinaria, en principio en el orden contencioso-administrativo, la protección y la defensa jurisdiccional de la au- 
tonomía local. Conforme a ello los Jueces y los Tribunales integrantes del Poder Judicial controlarán el respeto de dicha autonomía, tanto a través de la aplicación de la legalidad definitoria de las competencias locales, como en virtud de la toma en consideración del contenido principial del núcleo esencial de la autonomía local que la Constitución española garantiza. Ello trae como directa consecuencia que, cuando la vulneración de la autonomía local se residencie directamente en una norma con rango de ley, los Jueces y Tribunales ordinarios habrán de plantear la cuestión de inconstitucionalidad ante el Tribunal Constitucional, siempre, claro está, que se trate de normas postconstitucionales, pues respecto de las anteriores pueden los órganos judiciales apreciar, cuando tal sea el caso, su derogación como consecuencia de la aplicación de la disposición transitoria $3^{\underline{a}}$ de la Constitución española.

Situados ahora en el plano de la legalidad ordinaria, la actuación del Poder Público potencialmente lesiva de la autonomía local puede estar constituida tanto por actos administrativos singulares cuanto por disposiciones generales, y proceder tanto del Estado como de las Comunidades Autónomas o de otra Entidad Local (significadamente, de una o varias Diputaciones o de uno o varios Ayuntamientos).

Pues bien, el tipo de actuación pública que lesione la autonomía local y la Administración Pública de la que proceda han sido tomados en cuenta por el legislador ordinario en la configuración del proceso contencioso-administrativo en la Ley 29/1998, de 13 de julio, reguladora de la Jurisdicción Contencioso-Administrativa. Y, si bien es cierto que tal configuración no toma como referencia el hecho de que se pretenda la protección de la autonomía local en un concreto proceso, también lo es que en la clase de actos potencialmente lesivos de la autonomía local, ya procedan de otras Administraciones, ya de particulares, o en la defensa frente a tales actos con fundamento en la garantía institucional de la autonomía local, frecuentemente concurrirán unos caracteres específicos que harán aplicables las singularidades procesales que a continuación vamos a considerar.

B) LA TUTELA DE LA AUTONOMÍA LOCAL FRENTE A LAS VULNERACIONES PRODUCIDAS POR ACTUACIONES ADMINISTRATIVAS

\section{a) Las actividades administrativas impugnables.}

Respecto a la clase de actividad administrativa impugnable por lesionar la autonomía local, o cuya defensa se basa precisamente en la aplicación de tal principio, la Ley de la Jurisdicción Contencioso-Administrativa de 1998 admi- 
te la impugnación, no sólo de los actos administrativos y de las disposiciones generales de rango inferior a ley, sino asimismo la de la inactividad de la Administración, al igual que también contempla la posibilidad de recurrir frente a la vía de hecho (arts. 29 y 30 Ley de la Jurisdicción Contencioso-Administrativa). Basta la lectura de los artículos 55 a 62 de la Ley $7 / 1985$, de 2 de abril de 1985, Reguladora de las Bases del Régimen Local, para advertir que las relaciones interadministrativas (las que pueden establecerse entre el Estado, las Comunidades Autónomas y los Entes Locales) exigen un respeto de las competencias ajenas en el ejercicio de las propias que, en no pocas ocasiones, será fuente de conflictos en los que la autonomía local cobrará gran importancia. Estas consideraciones adquieren especial relevancia en aquellos supuestos en los que se impone al Estado o a la Comunidad Autónoma el deber de asegurar el cumplimiento de ciertas obligaciones a cargo de las Entidades Locales (art. 60 de la Ley Reguladora de las Bases del Régimen Local) o en aquellos casos en los cuales haya de hacerse uso de las facultades de coordinación de las actuaciones desarrolladas por diferentes Administraciones como consecuencia de la existencia de competencias distintas o diversificadas sobre un mismo sector de actividad administrativa.

\section{b) Los sujetos de las actividades administrativas impugnables.}

Las Entidades Locales Territoriales están legitimadas para impugnar los actos y disposiciones que afecten al ámbito de su autonomía procedentes del Estado o de las Comunidades Autónomas, así como los dictados por Organismos Públicos con personalidad jurídica propia vinculados al Estado o a las Comunidades Autónomas y los de otras Entidades Locales (art. 19.1.e Ley de Jurisdicción Contencioso-Administrativa).

Los litigios en los que una Entidad Local pretenda defender su autonomía frente al Estado, una Comunidad Autónoma u otra Entidad Local han de ser calificados de litigios entre Administraciones Públicas, lo cual lleva aparejadas algunas especialidades procesales, entre las que se encuentran:

* La necesidad de un previo requerimiento de anulación, derogación, cesación de la actividad o vía de hecho, modificación de la actuación material o inicio de actividad debida (art. 44.1 Ley de Jurisdicción Contencioso-Administrativa).

* Determinadas singularidades en cuanto al plazo de interposición (art. 46.6 Ley de Jurisdicción Contencioso-Administrativa). 
* Y, finalmente, la apelabilidad en todo caso de la Sentencia que resuelva las lites [art. 81.2.c) Ley de Jurisdicción Contencioso-Administrativa].

Cuando el acto que vulnera la autonomía local proceda de una Comunidad Autónoma o de un Ente Local sólo cabrá recurso de casación, contra la Sentencia que haya resuelto la impugnación contencioso-administrativa, si dicho recurso se fundamenta en normas de Derecho estatal o de Derecho comunitario europeo que hayan sido relevantes y determinantes del fallo de la Sentencia recurrida.

\section{C) LA TUTELA DE LA AUTONOMÍA LOCAL FRENTE A LAS DISPO- SICIONES GENERALES QUE LA LESIONEN}

Respecto de la impugnación de disposiciones generales la Ley de la Jurisdicción Contencioso-Administrativa ha introducido algunas especialidades que pueden resultar singularmente útiles en la defensa de la autonomía local, por más que no sean aplicables sólo a las impugnaciones de reglamentos estatales o autonómicos por lesionar tal autonomía. En efecto, además de atribuir la competencia para conocer de la impugnación directa de las disposiciones reglamentarias indicadas al órgano que culmina la organización judicial en el ámbito territorial de su aplicación (Tribunal Supremo, si el Reglamento sometido a enjuiciamiento procede del Gobierno de la Nación, o Tribunal Superior de Justicia, si hubiera sido dictado por el Consejo de Gobierno de una Comunidad Autónoma) se contienen reglas específicas para la impugnación indirecta de disposiciones generales, es decir, en relación con aquellos casos en los que la impugnación de un acto administrativo se funda en la ilegalidad de la disposición general aplicada. De esta manera, cuando la vulneración de la autonomía local se revela como existente en la disposición general a raíz del dictado de un acto concreto, la falta de impugnación directa de la disposición general en el breve plazo establecido no impedirá la depuración del Ordenamiento jurídico mediante la expulsión de la norma que vulnere la garantía institucional que nos ocupa. Así:

* Se regula la cuestión de ilegalidad, en virtud de la cual el órgano judicial que estima un recurso contencioso-administrativo indirectamente deducido contra una disposición general está obligado plantear su ilegalidad al órgano judicial que tiene la competencia para conocer del recurso directo contra aquélla (art. 27.1 Ley de Jurisdicción Contencioso-Administrativa).

* Cuando el órgano judicial que conoce del recurso indirecto tiene competencia para conocer también de la impugnación directa de la 
disposición general, al estimar el recurso debe anular, además del acto de aplicación, la disposición general aplicada (art. 27.2 Ley de la Jurisdicción Contencioso-Administrativa).

* El Tribunal Supremo puede anular cualquier disposición general al conocer, en cualquier grado, de cualquier recurso indirecto contra disposiciones generales (art. 27.3 Ley de Jurisdicción Contencioso-Administrativa).

* Siempre que se trata de una impugnación indirecta de una norma de rango inferior a la ley, contra la resolución que en ella se dicte cabe recurso de apelación o de casación (arts. 81.2.d y 86.3 Ley de la Jurisdicción Contencioso-Administrativa).

D) LA SUPRESIÓN DE LOS CONTROLES PREVIOS DE LEGALIDAD SOBRE LOS ACTOS Y DISPOSICIONES DE LAS CORPORACIONES LOCALES

Donde se puede observar un mayor cambio normativo como consecuencia del reconocimiento constitucional de la autonomía local es, precisamente, en la reestructuración de las posiciones previas de los Entes Locales frente al Estado y las Comunidades Autónomas, singularmente en cuanto a las relaciones de tutela de estas últimas Administraciones Públicas sobre las primeras. En efecto, la Ley Reguladora de las Bases del Régimen Local suprime los controles previos de legalidad respecto de los actos y disposiciones de las Corporaciones Locales, atribuyendo el control de tales actos y disposiciones a la Jurisdicción Contencioso-Administrativa. De acuerdo con este posicionamiento normativo no cabe ya la suspensión de los acuerdos de las Corporaciones Locales (salvo el supuesto excepcional contemplado en el art. 67 de la Ley Reguladora de las Bases del Régimen Local, que, en todo caso, exige la ulterior impugnación ante la Jurisdicción Contencioso-Administrativa del acuerdo suspendido por el Delegado del Gobierno), sino su impugnación ante los órganos judiciales competentes con previo requerimiento de anulación o sin él (arts. 65 y 66). Serán, en su caso, los indicados órganos judiciales los que accederán o no a la suspensión del acto o de la disposición que se impugne.

IV. EL TRIBUNAL CONSTITUCIONAL, GARANTE DE LA AUTONOMÍA LOCAL

A) LAS VÍAS PARA CONSEGUIR LA TUTELA DE LA AUTONOMÍA LOCAL POR EL TRIBUNAL CONSTITUCIONAL HASTA LA REFORMA INTRODUCIDA EN LA LEY ORGÁNICA DE ÉSTE POR LA LEY ORGÁNICA 7/1999, DE 21 DE ABRIL 
Como ya queda advertido, salvo que la Sentencia que en su caso se dicte por los órganos de la Jurisdicción ordinaria vulnere por irrazonabilidad o arbitrariedad el derecho a la tutela judicial efectiva (art. 24.1 C.E.), el sistema de defensa de la autonomía local se agota ante los Jueces y Tribunales que integran el Poder Judicial. Si el acto del Poder Publico lesivo de la autonomía local es un acto singular o una disposición general de rango inferior a la ley no cabe acudir, tras el agotamiento de la vía judicial, al recurso de amparo para la tutela de la autonomía local (excepto en el caso de que en la vía judicial se haya producido una vulneración del derecho fundamental a la tutela judicial efectiva -art. 24 C.E.-, según ya hemos avanzado). Si la lesión se sitúa en una norma con rango de Ley tan sólo cabrá sugerir al órgano judicial que esté conociendo del acto aplicativo que plantee la cuestión de inconstitucionalidad por lesión del principio de autonomía local, y no ha de olvidarse que, como con reiteración se ha afirmado (baste la referencia, por todas, a la STC 228/1998, de 1 de diciembre), tal planteamiento es una facultad (no una actuación debida u obligada) del órgano judicial, por lo cual la solicitud de que se efectúe no puede configurarse o hacerse valer (en caso de negativa a acceder a ella) como una pretensión autónoma de amparo.

Consecuentemente, hasta la reforma de 1999 de la Ley Orgánica del Tribunal Constitucional a la que inmediatamente vamos a hacer referencia, los Entes Locales no tenían posibilidad alguna de promover el planteamiento de un juicio de constitucionalidad directamente contra una norma con rango de Ley promulgada con posterioridad a la Constitución.

\section{B) EL CONFLICTO EN DEFENSA DE LA AUTONOMÍA LOCAL.}

\section{a) Consideraciones generales.}

La situación hasta aquí descrita ha cambiado sustancialmente a raíz de la promulgación de la Ley Orgánica 7/1999, de 21 de abril, con la que se ha introducido en la Ley Orgánica del Tribunal Constitucional un nuevo proceso constitucional, el conflicto en defensa de la autonomía local, regulado en los artículos 75.bis a 75.quinque de la Ley rectora de este Tribunal. Este nuevo proceso constitucional surge en el marco del denominado Pacto Local, con el que el Gobierno quiso potenciar la posición institucional y jurídica de los Entes Locales, y encuentra su cobertura jurídica, no exenta de discusiones doctrinales, en la llamada que el art. 161.1.d) de la Constitución realiza al específico instrumento de la ley orgánica para la atribución al Tribunal Constitucional de competencia para el conocimiento de materias no específicamente contempladas en las letras anteriores de este mismo apartado. 
El proceso constitucional que ahora reclama nuestra atención nace para permitir a los Entes Locales de existencia constitucionalmente garantizada (los Municipios y las Provincias) la impugnación directa de normas con rango de ley, tanto si proceden del Estado como si han sido dictadas por las Comunidades Autónomas, pero sólo en función de que resulten lesivas de la autonomía local. Cualquier otro tipo de acto o disposición general habrá de ser impugnado, como se ha dicho, ante la jurisdicción ordinaria, y ningún motivo distinto a la vulneración de la autonomía local puede encauzarse a través de este nuevo proceso constitucional.

\section{b) Legitimación para el planteamiento del conflicto.}

La legitimación no se confiere de manera individual a todos y a cada uno de los más de ocho mil Municipios de España o a todas y a cada una de las cuarenta y cuatro Diputaciones Provinciales de nuestro país. La Ley Orgánica 7/1999 ha previsto un sistema de legitimación muy selectivo, en el que se conjugan población, territorio y Entes Locales. Así, con arreglo al artículo 75.ter.1. LOTC, sólo podrán plantear el conflicto en defensa de la autonomía local:

«a) El Municipio o Provincia que sea destinatario único de la ley.

b) Un número de Municipios que supongan al menos un séptimo de los existentes en el ámbito territorial de aplicación de la disposición con rango de ley, y representen como mínimo un sexto de la población oficial del ámbito territorial respectivo.

c) Un número de Provincias que supongan al menos la mitad de las existentes en el ámbito territorial de aplicación de la disposición con rango de ley, y representen como mínimo la mitad de la población oficial».

\section{c) Tramitación del conflicto.}

De acuerdo con el artículo 75.ter.2 LOTC la tramitación del conflicto ha de comenzar con «el acuerdo del órgano plenario de las Corporaciones Locales» adoptado por «mayoría absoluta del número legal de miembros de las mismas». Obtenido ese acuerdo [y dentro de los tres meses siguientes al día de la publicación de la ley que pretenda impugnarse (art. 75.quater.1)], «deberá solicitarse dictamen, [...] preceptivo pero no vinculante, del Consejo de Estado u órgano consultivo de la correspondiente Comunidad Autónoma, según que el ámbito territorial al que pertenezcan las Corporaciones Locales corresponda a varias o a una Comunidad Autónoma», incumbiendo al Consejo 
de Estado la evacuación del preceptivo dictamen si la Comunidad Autónoma de que se trate no dispone de órgano consultivo propio (art. 75.ter.3 LOTC).

Por fin, «dentro del mes siguiente a la recepción del dictamen [...] los Municipios o Provincias legitimados podrán plantear el conflicto ante el Tribunal Constitucional, acreditando el cumplimiento de los requisitos exigidos en el artículo anterior y alegándose los fundamentos jurídicos en que se apoya» (art. 75.quater.2 LOTC). Con ello se tendrá por planteado el conflicto, si bien «el Tribunal podrá acordar, mediante auto motivado, la inadmisión del mismo por falta de legitimación u otros requisitos exigibles y no subsanables o cuando estuviere notoriamente infundada la controversia suscitada» (art. 75.quinque.1 LOTC). El Tribunal puede, por tanto, inadmitir también por motivos materiales, lo que vendría a constituir, prácticamente, una desestimación anticipada.

En otro caso se tendrá por admitido a trámite el conflicto, debiendo darse traslado de su planteamiento, «en el término de diez días, [...] a los órganos legislativo y ejecutivo de la Comunidad Autónoma de quien hubiese emanado la ley, y en todo caso a los órganos legislativo y ejecutivo del Estado", disponiendo todos ellos de veinte días para personarse y formular alegaciones (art. 75.quinque.2 LOTC).

\section{d) Canon de enjuiciamiento.}

Los artículos de la Ley Orgánica del Tribunal Constitucional dedicados a la disciplina del conflicto en defensa de la autonomía local no dicen nada sobre esta particular cuestión. Cuando más identifican como objeto de protección «la autonomía local constitucionalmente garantizada» (art. 75.bis.1). Quiere decirse con ello que, desde luego, el canon utilizable para la resolución de estos conflictos ha de estar constituido por los preceptos constitucionales que establecen y garantizan esa autonomía (en concreto, los artículos $137,140,141$ y 142). Pero a estos preceptos deben sumarse, por imperativo del artículo 149.1.18 a de la Constitución, las leyes del Estado reguladoras de las bases del régimen jurídico de la Administración Pública Local, singularmente la Ley 7/1985, de 2 de abril, Reguladora de las Bases del Régimen Local, en cuanto a su través se delimitan las competencias del Estado al establecer lo básico y, negativamente, las correspondientes a las Comunidades Autónomas al configurar el ámbito en el que cabe la legislación de desarrollo.

Ahora bien, la utilidad de la normativa básica de régimen local como canon de constitucionalidad despliega diferentes efectos según que la norma en- 
juiciada en el conflicto en defensa de la autonomía local proceda del Estado o de las Comunidades Autónomas.

En el primer caso aquella normativa no condiciona la validez de la legislación estatal posterior, pues la Constitución no reserva la materia local a favor de una ley determinada, de manera que rige en toda su extensión la lógica de la preeminencia de la ley posterior frente a sus antecedentes. Ello supone que los conflictos en defensa de la autonomía local que se susciten contra leyes estatales sólo podrán resolverse en virtud de los preceptos constitucionales en los cuales se consagra o, al menos, se perfila la autonomía local, sin encontrarse fuera de la Constitución otros parámetros de enjuiciamiento.

En cambio, tratándose de una ley autonómica, la infracción de la normativa básica de régimen local supondrá su inconstitucionalidad, pero no en todos los casos necesariamente por infracción de la autonomía local, sino en ocasiones sólo por invasión de la competencia del Estado para disciplinar las bases de una determinada materia. Y ello porque la Ley Reguladora de las Bases del Régimen Local únicamente es condición de validez de la ley autonómica, en lo que a la autonomía local se refiere, en cuanto aquélla tenga de delimitación de la autonomía local constitucionalmente garantizada. Así lo ha dicho el Tribunal Constitucional en la STC 109/98, de 21 de mayo (fundamento jurídico 2):

«[...] no toda incidencia en la esfera competencial de la entidad local debe reputarse lesiva de la mencionada garantía institucional, toda vez que ésta no se concibe como una garantía absoluta que impida toda suerte de afectación de la esfera de competencias legalmente asignadas, sino únicamente aquéllas que menoscaben o vulneren el núcleo esencial e indisponible de la autonomía Provincial, sin el cual ésta no presentaría los caracteres que la hacen recognoscible como institución».

La ley autonómica infractora de la Ley Reguladora de las Bases del Régimen Local será, pues, inconstitucional, pero no en todos los casos por lesionar la autonomía local constitucionalmente garantizada, aunque siempre (además o únicamente) por no respetar la distribución de competencias operada en el artículo 149.1.18 de la Constitución. Ahora bien, conviene no olvidar que los sujetos legitimados lo están únicamente para defender la autonomía local, sin que ello, por sí sólo, les constituya en garantes de la distribución de competencias entre el Estado y las Comunidades Autónomas, salvo en el caso extremo de que en virtud de dicha distribución resulte comprometida la autonomía de los Entes Locales. 
En definitiva, el canon de enjuiciamiento aplicable por el Tribunal Constitucional ha de tomar en consideración la procedencia, estatal o autonómica, de la norma desencadenante del conflicto.

\section{e) Resolución del conflicto.}

La Ley Orgánica del Tribunal Constitucional prevé un llamativo sistema de eventual doble sentencia para la resolución del conflicto en defensa de la autonomía local. Con arreglo al artículo 75.quinque.5 LOTC, «la sentencia declarará si existe o no vulneración de la autonomía local constitucionalmente garantizada, determinando, según proceda, la titularidad o atribución de la competencia controvertida, y resolverá, en su caso, lo que procediere sobre las situaciones de hecho o de derecho creadas en lesión de la autonomía local». Sin embargo de esta sola declaración no se sigue, sin más, la inconstitucionalidad de la ley infractora. En efecto, el apartado 6 del mismo artículo establece que «la declaración, en su caso, de inconstitucionalidad de la ley que haya dado lugar al conflicto requerirá nueva sentencia si el Pleno decide plantearse la cuestión tras la resolución del conflicto declarando que ha habido vulneración de la autonomía local». Cuestión que se substanciará por el procedimiento previsto para las cuestiones de inconstitucionalidad promovidas por los Jueces y Tribunales ordinarios y con sus mismos efectos.

Es posible, en consecuencia, que la declaración de vulneración de la autonomía local no vaya seguida de una declaración de inconstitucionalidad de la ley vulneradora (y de la consiguiente declaración de su nulidad, en los términos del artículo 39 al que se remite el apartado 6 del artículo 75.quinque LOTC). Bien porque el Pleno que hace la primera declaración decida no plantearse la cuestión de inconstitucionalidad de la ley infractora, bien porque, habiendo decidido hacerlo, la autocuestión se resuelva en sentido favorable a la ley (algo que no puede descartarse sin más, siquiera sea sólo porque entre uno y otro pronunciamientos del Pleno ha podido suceder, por ejemplo, que haya cambiado la composición personal de éste como consecuencia de su renovación parcial, por poner el caso más extremo).

Las dudas y problemas que suscitan estas previsiones legislativas no son, desde luego, pocas ni de escasa relevancia. Habrá que esperar a los concretos pronunciamientos del Tribunal con ocasión de los conflictos que ya se han planteado (una media docena, hasta el día de hoy) para perfilar cabalmente el sentido y el alcance de este nuevo procedimiento. Y no menos para valorar si, en definitiva, con él gana efectivamente el nivel de protección de la autonomía local garantizada por la Constitución. 